\title{
Diversification of Lighting Intensity in a Dusty Livestock Room During the Cleaning Process of Reflector Screens
}

\author{
Henryk Żelazny ${ }^{1}$ \\ 1 Faculty of Materials, Civil and Environmental Engineering, University of Bielsko-Biala, Willowa 2, 43-309 \\ Bielsko-Biala, Poland \\ e-mail: hzelazny@ath.bielsko.pl
}

\begin{abstract}
The livestock rooms with the systems for feeding dry feeds using feeder pipelines are characterized by a relatively high concentration of dust. The studies on the shaping of artificial lighting intensity were carried out in an experimental, non-bedding pig fattening house. In order to improve the lighting, the animal room was modernized by lining the ceiling and walls with aluminum foil. It constitued a reflector screen when light was on, which, however, over time became covered with dust coming from the mechanically fed dry feeders. For the assessment of brightness in the production hall, five equally spaced measuring stations were placed in the pens and five similarly spaced stations were set in the corridor. The intensity of lighting (brightness) was measured with the L-20A lux-meter. The measurements were carried out after a six-month use of the liner, when it was significantly contaminated with the dry fodder particles. As part of operational tests, the differentiation of brightness between the individual stands and gradual changes in lighting at various stages of aluminum foil cleaning were checked: washing the external wall with detergents, washing all the walls in the room and the entire interior, including the ceiling was carried out. Before wet cleaning the reflector screens, a significant differentiation of the brightness between the stands in the pens was observed - it ranged from 134.1 Lx to 176.0 Lx, which indicates uneven pollution of the internal surfaces of building partitions. Similarly, significant discrepancies in the lighting intensity were found on the corridor floor. The values ranged between 50.3 Lx and 65.8 Lx. When washing the next partitions, the average illumination values in the pen area dropped unexpectedly, and the final drop after removing the dust from all the walls and ceiling was $2.8 \%$. A similar tendency was observed in the communication-drive corridor. In this area, the brightness decreased by as much as $4.1 \%$. The reason for the decrease in visual comfort was the mattifying of screens caused by grinding of particles during washing. Therefore, it would be necessary to undertake the research on the removal of dust from the reflector screens using another method, for example mechanical dusting.
\end{abstract}

Keywords: dust, building for livestock, lighting, illuminance, aluminum foil, internal surfaces

\section{INTRODUCTION}

The breeding rooms in livestock buildings need to be lit, among others, during grazing and handling the animals, including for example cleaning pens and driving animals down the corridors to catwalks or other rooms. These processes can take place in the early morning or evening hours, and in the transitional and winter periods, so the only possible way to maintain the proper photoclimate inside is to use artificial lighting. In this way, the maintained visual comfort ensure safe use such objects.
Due to the fact that approximately $20 \%$ of the world's energy is used for lighting [12], the socalled secondary light sources, such as ceilings and walls, should be used more often to reduce energy consumption of buildings in rooms [2]. They help to reflect the light and increase the intensity of lighting in the interior. Large albedo finishing materials can reduce the number of light points in the room. A similar phenomenon is also observed outside objects, where the intensity of sunlight entering through the windows can depend greatly on the light reflected from the ground and other buildings [24]. Aluminum foil is the material that 
reflects the light well and can be used as an internal lining of building partitions. The use of this material as a screen to reflect light in construction is not common, and there are hardly any publications available on the effectiveness of such solutions. Instead, general research is conducted on the methods for determining the light reflectance value for reflective materials that are useful for interior finishing [28]. However, aluminum foil has been used to reflect the heat from building partitions to reduce the energy losses from a building [25]. In agriculture, various screen materials are widely used to save energy by reducing the heat radiation losses during the night and to reduce the solar radiation during the day [7]. For example, reflective aluminum screens were used to reduce the solar radiation and thus improve the physiology of cultivation, growth and plant performance in a grapefruit orchard [8]. When the aluminum foil is used to improve the lighting in livestock buildings, the effectiveness of this inner liner can be reduced by the dust particles settling on it. Together with ammonia and complex of compounds responsible for the characteristic odor associated with animal production, these impurities are a consequence of the microbiological degradation of manure and litter [13]. The feeding process can also contribute to particulate emissions. The size of particles and the size distribution differ depending on the source and whether they are of mineral or organic origin [4]. In turn, the concentration of the dust depends on various factors, which include: the category of animals, their activity, type of bedding and season [11]. In mechanically ventilated buildings, this concentration is highly variable in terms of spatial distribution [1] with the variation up to 30 times between the lowest and the highest value [27]. In the studies evaluating this type of contamination in building for pigs, the average mass concentration of dust was 0.72 $\mathrm{mg} / \mathrm{m}^{3}$, ranging from 0.12 to $2.14 \mathrm{mg} / \mathrm{m}^{3}$ [16]. In another experiment, carried out in a building for fattening pigs, the concentration of the inhaled dust was at the level of $0.19 \mathrm{mg} / \mathrm{m}^{3}$ [23]. The amount of dust in animal rooms is also variable over time. For example, it was found that in buildings for pigs, the maximum concentration of dust occurs during feeding and an hour after the increased animal activity with the lights switched on [9]. Unfortunately, dust also acts as a carrier of microorganisms that float in large quantities in the systems intended for animal production, which poses the risk of infection for the people and nearby animals and even the animals kept on other farms are at the risk of infection [31]. Therefore, the floating dust in livestock rooms raises concerns for the health of people working therein and for the welfare of animals [19, 23]. There is an increased incidence of respiratory disorders among the workers handling animals [26] (This is one of the reasons why agricultural work is considered the main risk factor for occupational diseases [3]). Therefore, in order to protect the human respiratory system, the dust particles in buildings for animals are monitored [14]. In order to reduce the amount of dust in the livestock housing, different solutions are used, e.g. electrostatic precipitators [20], recirculating air filters [5], electrostatic discharge systems (ESDS) [18], water spraying [22], oil spraying on the floor [29, $30]$ and spraying with a mixture of rapeseed oil and water [22]. In addition, various feed additives [17] may be used to keep the dust concentration low, for example the animal fat [22]. The research has also confirmed that an important way to remove particulate matter from the air in a livestock building is the deposition of dust on the internal surfaces [6], and dust removal methods include cleaning of these dusty surfaces [17].

The aim of the operational tests was to assess the effectiveness of wet dust removal from a light-reflecting aluminum foil lined on the inner surfaces of a pig fattening house - with regard to improving the artificial lighting intensity in the pens and in the corridor.

\section{MATERIALS AND METHODS}

The investigations into the artificial lighting intensity were carried out in an experimental, mechanically ventilated, single-row non-bedding pig farm, owned by the Experimental Station in Grodziec Śląski, southern Poland. In order to improve the illumination, the animal room was modernized by lining the ceiling and walls (save for a $1 \mathrm{~m}$ high belt up from the floor, as the animals could damage the liner at this height) with aluminum foil. It consituted a reflector screen when the room was lit, but over time the screen became covered with the dust coming mainly from the mechanical dry feeders (the facility used a full floor farming system, i.e. without litter facilitating the formation of dust). In order to measure the brightness in the production hall, 5 evenly spaced measuring stations were set up in the 
pens, located exactly under the five lamps fixed to the flat roof. Similarly, in the corridor, 5 stands were designated in the places closest to the light points and with spaced like in the pens. Artificial lighting was provided by fluorescent lamps with the output of $20 \mathrm{~W}$, mounted by two in transparent hanging frames of the same shape, providing the so-called direct lighting. The artificial lighting intensity (brightness) was measured with the L-20A lux-meter. The measurements were carried out after a six-month exploitation of the liner which was significantly contaminated with dry fodder particles fed through pipelines. The experiment was conducted as an operational test; thus, the concentration and type of dust were not identified. Rather, the differentiation of brightness between individual stands was checked and the gradual changes in lighting were monitored at various stages of cleaning the aluminum foil with high albedo, i.e. after washing the external wall with detergents (Fig. 1), then after washing all the walls in the room, i.e. one external and three internal, and then after washing the entire interior, including the ceiling. In the general lighting markings, the active plane of the instrument head in the pens was set so that it coincided with the measuring plane set $0.85 \mathrm{~m}$ above the floor. While measuring the corridor lighting, it was placed directly on the floor, in accordance with the principle of making measurements in passageways. The measurement results were read in such a way as not to obscure the receiver.

\section{RESULTS AND DISCUSSION}

The values of the artificial lighting intensity on stand number 1 in the fattening pigs pen zone and stand number 1 in the communication and drive passage, showing the changes in brightness during the process of removing dust from the aluminum foil, are shown in Figure 2.

Figure 3 presents the results pertaining to the measurements of artificial lighting intensity in the pens and in the corridor for stands number 2 .

The influence of washing the reflector screens on the brightness in the central part of the inventory room, i.e. measured at stations number 3 , is presented in Figure 4.

Figure 5 shows the values of the artificial lighting intensity marked in the measuring points number 4 , set up in a row of pens and in the communication and drive passage, respectively.

The artificial light intensity values at measuring stands number 5 , measured at various stages of cleaning the liner, are included in Figure 6.

Prior to wet cleaning the reflector screens, a significant differentiation of the brightness between the individual measuring stands set up in the pens was observed, which ranged from 134.1 Lx to 176.0 Lx. This indicates the uneven settlement of dust on the internal surfaces of building partitions and confirms the conclusions from other studies that there is a high spatial variability of the concentration of these dusts in the livestock buildings $[1,26]$. Similarly, significant discrepancies in the lighting intensity were found on the corridor floor. The values ranged between $50.3 \mathrm{Lx}$ and $65.8 \mathrm{Lx}$. As already mentioned, this was due to the different degree of dust settling on the reflector screens, because unlike gaseous pollutants, dust is not distributed evenly in pig housing [26], and the assessment of its spatial distribution in mechanically ventilated interiors poses some problems due to the lack of appropriate sampling techniques [27].

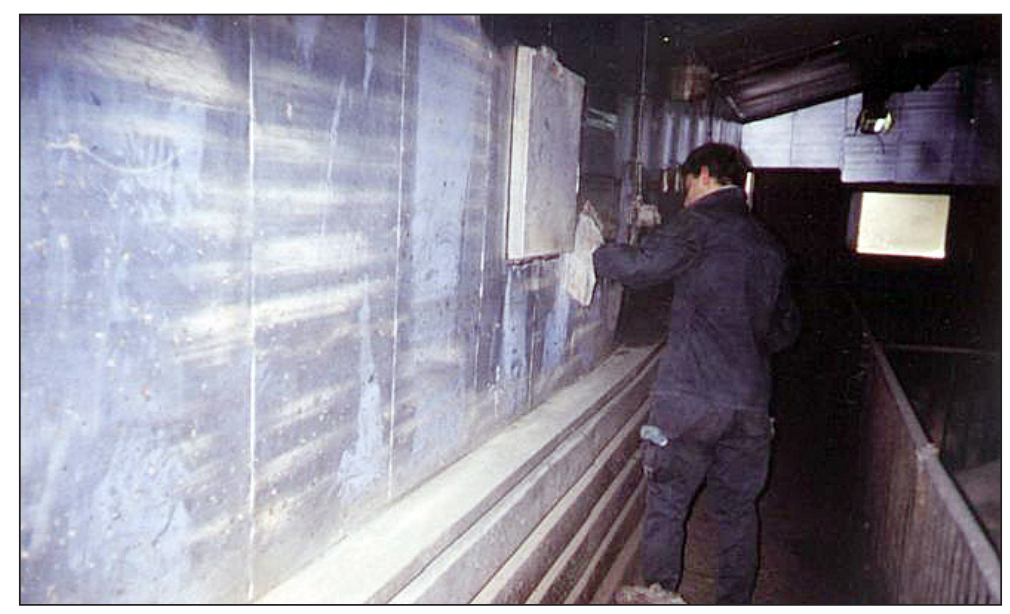

Fig. 1. Washing dusted reflective screen, lined on all walls and ceiling of the livestock building 


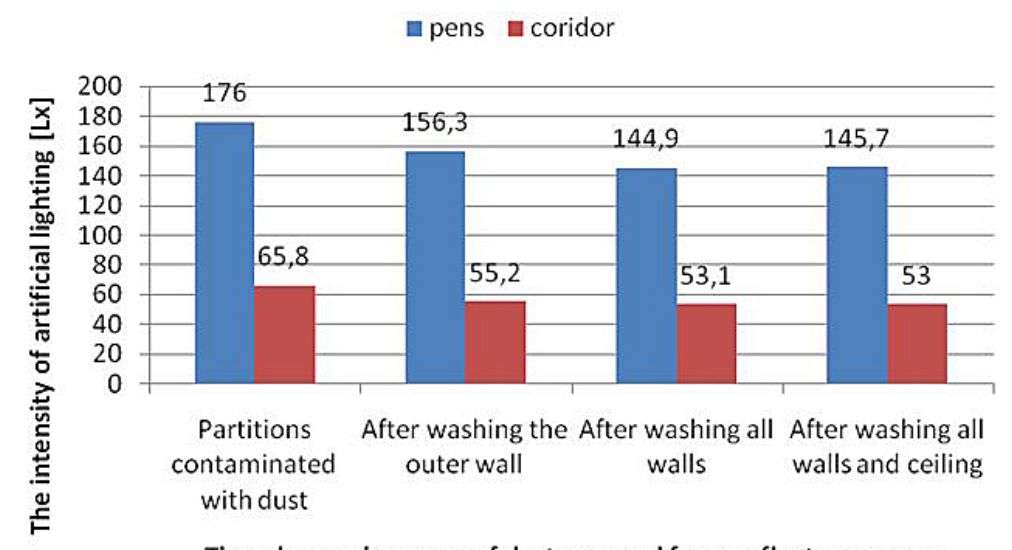

The advanced process of dust removal from reflector screens

Fig. 2. Intensity of artificial lighting in the pens and in the fattening house corridor in measuring points number 1, measured as the light-reflecting liner was covered with dust and after washing the subsequent partitions

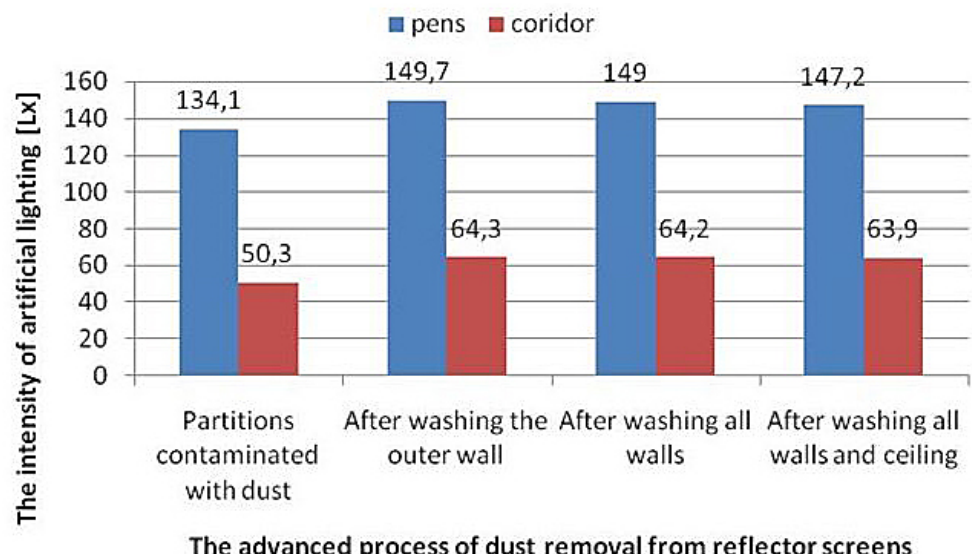

Fig. 3. Artificial lighting intensity in pens and in corridor of a fattening house in measuring points number 2 at various stages of wet cleaning the reflector screens

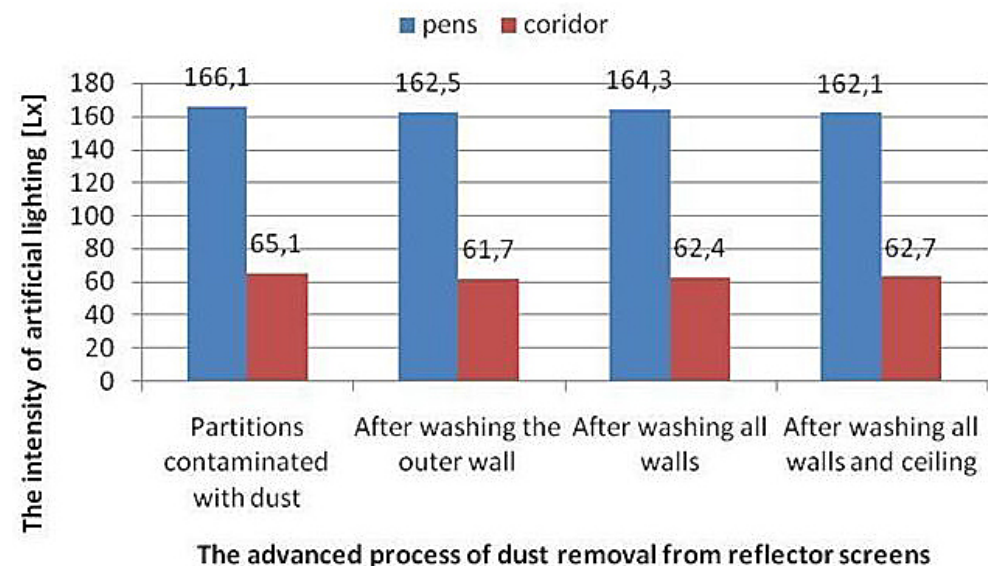

Fig. 4. Intensity of artificial lighting in pens and in corridor of the fattening house at measuring points number 3 , i.e. in the middle part of the inventory room, where dust was gradually removed from the inner reflecting surfaces

After washing the aluminum foil glued to the external wall, there was a slight increase in brightness at the two measuring stands in the pens (number 2 and 5). However, in the other three points, a decrease in the value of this photometric parameter was noted. At stand 4, the lux-meter showed $150.8 \mathrm{Lx}$ before the partition was cleaned, and only $132.0 \mathrm{Lx}$ following the cleaning. Similarly 


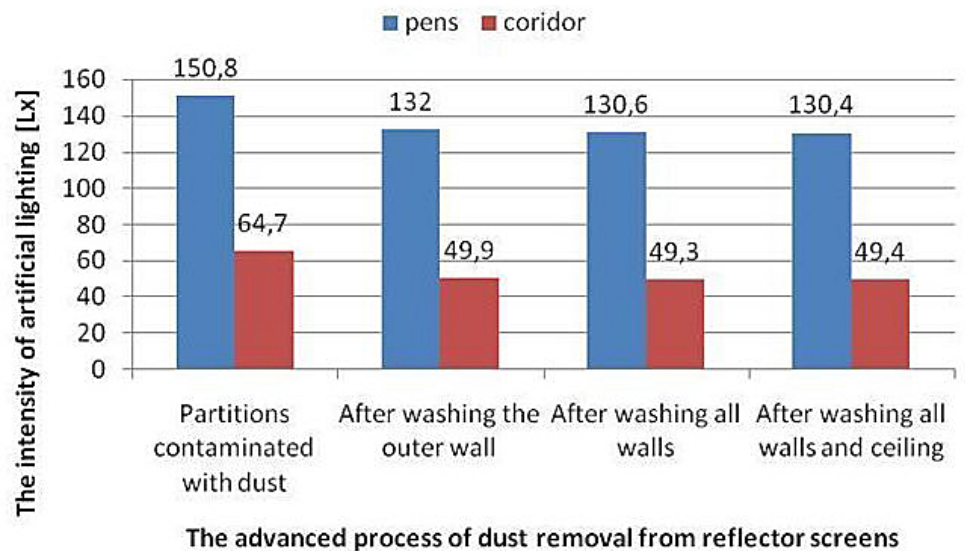

Fig. 5. Changes in the intensity of artificial lighting in pens and fattening corridor, measured at measuring stands number 4 , when washing subsequent walls lined with reflector screens

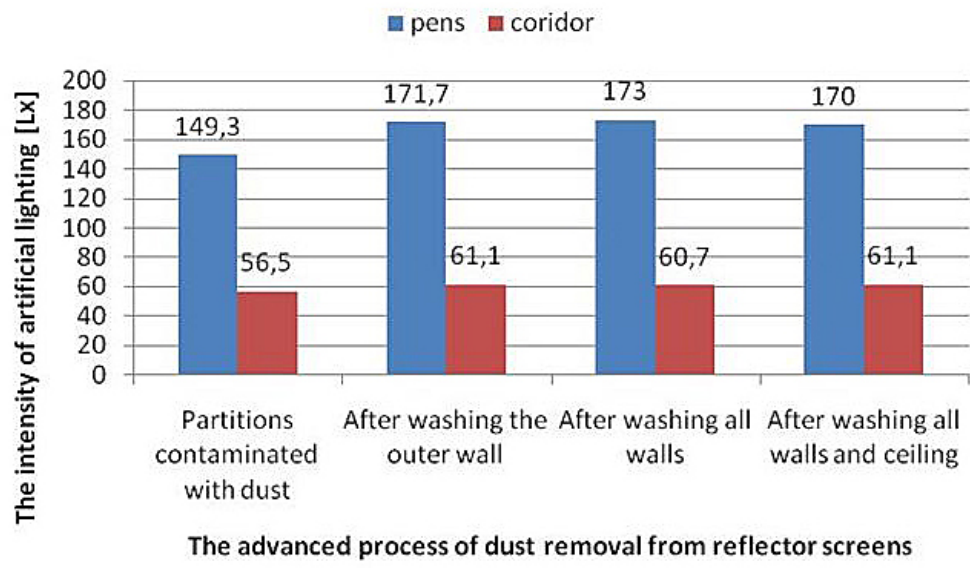

Fig. 6. Intensity of artificial lighting recorded at measuring points number 5 during various stages of cleaning the aluminum foil in pens and in coridor

unexpected results were obtained for the communication passage where the lighting intensity increased by $28 \%$ at one measuring stands, while at the second the increase was only $8 \%$. However, at the remaining three measurement points, there was a decrease in the quality of visual comfort, i.e. a decrease in brightness was recorded. The author is not aware of any reports from the studies on the impact of removing dust from the internal housing surfaces of housing on improving lighting; hence, referring to the results of other researchers poses a difficulty. Research centers assess the performance of reflectors in other settings, e.g. in optical devices [10]. In the past, aluminum foil and plastic litter covering $57-83 \%$ of the soil, were tested for their effectiveness in protecting cucumber and potato crops from winged aphids [15]. The influence of the light-reflecting litter made from aluminum foil and oat straw on carrots was also studied [21].
Washing the dust particles from the three remaining, internal walls did not contribute to the improvement of artificial lighting in the fattening house - its average value from all measuring stands in the pens decreased by as much as $18 \%$ compared to the initial state, i.e. before the reflector screens had been cleaned. In the corridor, the brightness grew minimally from $61.7 \mathrm{Lx}$ to 62.4 Lx only in its central part, i.e. at station 3.

Cleaning all the partitions, i.e. the walls and the ceiling, contributed to the increase in light intensity, as compared to the initial state, only at two stand located in the pen area. At one, the brightness increased from 134.1 Lx to $147.2 \mathrm{Lx}$, and at the second - from 149.3 Lx to $170.0 \mathrm{Lx}$. The same tendency was observed in the communication passage - compared to the initial state, after washing all the partitions, there was an increase in light intensity at two measuring stands, while the other three recorded decreases. No 
improvement in the photoclimate was observed in the animal zone or in the communication-driving passage after the removal of dust from the aluminum foil lining the internal surfaces of the fattening house. This conclusion is based on the averaged values of illuminance obtained from all the measuring points set in the pens. The values decreased successively when washing the partitions - from 155.4 Lx to $154.4 \mathrm{Lx}$ after the first cleaning stage, to $152.4 \mathrm{Lx}$ after the second stage and to $151.1 \mathrm{Lx}$ once all the reflector screens were cleaned. As a result of cleaning the aluminum foil, the lighting intensity in the pens dropped by $2.8 \%$. In the communication passage, the average brightness before removing the dust from the walls and ceiling was $60.5 \mathrm{Lx}$, and after the liner was washed with detergents, it decreased to 58.0 Lx, i.e. by $4.1 \%$. It is believed that this may have been caused by the formation of thin streaks of smeared fodder particles which were clearly visible once the reflector screens had dried and which caused the mattifying of the reflecting surfaces. In addition, there were significant differences in the lighting intensity between individual test stands set up in the pens (170.0 Lx and 130.4 Lx) and between the measurement points in the corridor (63.9 Lx and 49.4 Lx), which confirms the other reports of a large spatial variability of dust concentration in mechanically ventilated rooms.

\section{CONCLUSIONS}

On the basis of the tests carried out, the following can be formulated

a) statements:

1. a significant difference in brightness was observed between the individual measurement stands set up in pens and in the corridor, which proves the uneven settlement of dust on the internal surfaces of building partitions and confirms the reports from other tests performed in mechanically ventilated buildings,

2. after cleaning all the reflector screens, the average value of artificial lighting intensity in the tested fattening house decreased by $2.8 \%$,

3 . as a result of cleaning the aluminum foil, the brightness in the communication-driving corridor decreased by as much as $4.1 \%$;

b) conclusions:

1. wet cleaning of the aluminum foil screens applied to improve the visual comfort did not contribute to the increase for the reflection of light rays and did not improve the interior lighting in the experimental livestock building, 2. washing the light reflecting liner resulted in the formation of a very thin layer of molten dust and water on its surface, which dulled of the aluminum foil and reduced its ability to reflect the light,

3. further research should be undertaken on the effectiveness of improving the albedo of dustcontaminated reflector screens in livestock buildings, but using other dust removal methods, for example mechanical vacuuming.

\section{REFERENCES}

1. Barber E.M., Dawson J.R., Battams V.A., Nicol R.A.C. 1991. Spatial Variability of Airborne and Settled Dust in a Piggery. Journal of Agricultural Engineering Research, 50, 107-127.

2. Bąk J., 2000. Apartment lighting. Publisher of Science and Technology, Warsaw. (Oświetlanie mieszkań. Wydawnictwo Naukowo-Techniczne, Warszawa).

3. Berger I., Schierl R., Ochmann U., Egger U., Scharrer E., Nowak D. 2005. Concentrations of Dust, Allergens and Endotoxin in Stables, Living Rooms and Mattresses from Cattle Farmers in Southern Bavaria. Ann Agric Environ Med. 12(1), 101-107.

4. Cambra-López M., Torres A.G., Aarnink A.J.A., Ogink N.W.M. 2011. Source Analysis of Fine and Coarse Particulate Matter from Livestock Houses. Atmospheric Environment, 45 (3), 694-707.

5. Carpenter G.A. Fryer J.T. 1990. Air Filtration in a Piggery: Filter Design and Dust Mass Balance. Journal of Agricultural Engineering Research, 46, 171-186.

6. Chen Y.C., Barber E.M., Zhang Y., Besant R.W., Sokhansanj S. 1999. Methods to measure Dust Production and Deposition Rates in Buildings. Journal of Agricultural Engineering Research, 72 (4), 329-340.

7. Cohen S., Fuchs M. 1999. Measuring and Predicting Radiometric Properties of Reflective Shade Nets and Thermal Screens. Journal of Agricultural Engineering Research, 73 (3), 245-255.

8. Cohen S., Raveh E., Li Y., Grava A., Goldschmidt E.E. 2005. Physiological responses of leaves, tree growth and fruit yield of grapefruit trees under reflective shade screens. Scientia Horticulturae, 107 (1), 25-35.

9. Costa A., Borgonovo F., Leroy T., Berckmans D., Guarino M. 2009. Dust Concentration Variation in Relation to Animal Activity in a Pig Barn. Biosystems Engineering, 104 (1), 118-124. 
10. Dunn C.G., Bolon R.B., A. S. Alwan A.S., Stirling A.W. 1971. A Scanning Electron Microscope Study of Etched Aluminum Foil for Electrolytic Capacitors. Journal of the Electrochemical Society, 118 (2), 381-390.

11. Ellen H.H., Bottcher R.W., von Wachenfelt E., Takai H. 2000. Dust Levels and Control Methods in Poultry Houses. Journal of Agricultural Safety and Health, 6(4), 275-282.

12. Görgülü S., Ekren N. 2013. Energy Saving in Lighting System with Fuzzy Logic Controller which Uses Light-Pipe and Dimmable Ballast. Energy and Buildings, 61, 172-176.

13. Homidan A.A.L., Robertson J.F., A.M. 2003. Review of the Effect of Ammonia and Dust Concentrations on Broiler Performance. World's Poultry Science Journal, 59 (3), 340-349.

14. Li X.W. 2008. Effects of Dust and Contaminants in Animal Buildings on Human Health and Control Strategies. Journal of Environmental Science and Health. Part A: Environmental Science and Engineering and Toxicology, 32 (9-10), 2449-2469.

15. Loebenstein G., Alper M, Levy S., Palevitch D., Menagem E. 1975. Protecting Peppers from AphidBorne Viruses with Aluminum Foil or Plastic Mulch. Phytoparasitica, 3 (1), 43-53.

16. Maghirang R.G., Puma M.C., Liu Y., Clark P. 1997. Dust Concentration and Particle Size Distribution in an Enclosed Swine Nursery. Transactions of the ASAE, 40(3), 749-754.

17. Maghirang, R.G., Riskowski, G.L., Christianson, L.L., Manbeck, H.B. 1995. Dust Control Strategies for Livestock Buildings - a review. ASHRAE Transactions, 101 (2), 1161-1168.

18. Nicolai R.E., Hofer B. 2008. Swine Finishing Barn Dust Reduction Resulting from an Elektrostatic Space Discharge System. Livestock Environment VIII, 31 August - 4 September 2008, Iguassu Falls, Brazil 701P0408, pp.unpaginated ref. 21.

19. Pedersen S., Nonnenmann M., Rautiainen R., Demmers T.G.M., Banhazi T., Lyngbye M. 2000. Dust in Pig Buildings. Journal of Agricultural Safety and Health, 6(4), 261-274.

20. Rosentrater K. 2013. Performance of an Electrostatic Dust Collection System in Swine Facilities. Agricultural Engineering International: the CIGR Journal of Scientific Research and Development, 1-10.

21. Setiawan D.P., Ragsdale D.W. 1987. Use of Aluminum-Foil and Oat-Straw Mulches for Controlling Aster Leafhopper, Macrosteles Fascifrons
(Homoptera: Cicadellidae), and Aster Yellows in Carrots. The Great Lakes Entomologist, 20 (2), 103-109.

22. Takai H., Pedersen S. 2000. A Comparison Study of Different Dust Control Methods in Pig Buildings. Applied Engineering in Agriculture, 16 (3), 269-277.

23. Takai H., Pedersen S., Johnsen J.O., Metz J.H.M., Groot Koerkamp P.W.G., Uenk G.H., Phillips V.R., Holden M.R., Sneath R.W., Short J.L., White R.P., Hartung J., Seedorf J., Schröder M., Linkert K.H., Wathes C.M. 1998. Concentrations and Emissions of Airborne Dust in Livestock Buildings in Northern Europe. Journal of Agricultural Engineering Research, 70 (1), 59-77.

24. Tregenza P.R. 1995. Mean Daylight Illuminance in Rooms Facing Sunlit Streets. Building and Environment, 30 (1), 83-89.

25. Tyutikov V.V, Smirnov N.N., Lapateev D.A. 2016. Analysis of Energy Efficiency from the Use of Heat-Reflective Window Screens in Different Regions of Russia and France. Procedia Engineering, 150, 1657-1662.

26. Wang X., Zhang Y., Riskowski G.L., Ellis M. 2002. Measurement and Analysis of Dust Spatial Distribution in a Mechanically Ventilated Pig Building. Biosystems engineering, 81 (2), 225-236.

27. Wang X., Zhang Y., Zhao L.Y., Riskowski G.L. 2000. Effect of Ventilation Bate in Dust Spatial Distribution in a Mechanically Ventilated Airspace. Transactions of the ASAE, 43(6), 1877-1884.

28. Yuan J., Emura K., Farnham C. 2014. A Method to Measure Retro-reflectance and Durability of Retro-Reflective Materials for Building Outer Walls. Journal of Building Physics, 38 (6), 500-516.

29. Zhang Y., Nijssen L., Barber E. M., Feddes J.J.R., Sheridan M. 1994. Sprinkling Mineral Oil to Reduce Dust Concentration in Swine Buildings. ASHRAE Transactions, 100 (2), 1043-1050.

30. Zhang Y., Tanaka A., Barber E.M., Feddes J.J.R.1996. Effects of Frequency and Quantity of Sprinkling Canola Oil on Dust Reduction in Swine Buildings. Transactions of the ASAE, 39 (3), 1077-1081.

31. Zhao Y., Aarnink A.J.A., De Jong M.C.M., Groot Koerkamp P.W.G. 2014. Airborne Microorganisms from Livestock Production Systems and Their Relation to Dust. Critical Reviews in Environmental Science and Technology, 44 (10), 1071-1128. 